\title{
A Validated Liquid Chromatography-Tandem Mass Spectrometry Coupled with Liquid-Liquid Extraction for Indacaterol Quantitation in Human Plasma
}

\author{
Wesam G. Ammari ${ }^{1, *}$, Zainab Al-Qadhi ${ }^{1}$, Mohammad Khalil ${ }^{2}$, Rabab Tayyem ${ }^{2}$, Samir Qammaz $^{1}$, \\ Ghaleb Oriquat $^{1}$, Iman A. Basheti ${ }^{3}$, Henry Chrystyn ${ }^{4}$ \\ ${ }^{1}$ School of Pharmacy and Medical Sciences, Al-Ahliyya Amman University, Jordan \\ ${ }^{2}$ ACDIMA Centre for Bioequivalence and Pharmaceutical Studies, Jordan \\ ${ }^{3}$ School of Pharmacy, Applied Sciences University, Jordan \\ ${ }^{4}$ School of Applied Sciences, University of Huddersfield, United Kingdom
}

Copyright (C) 2015 Horizon Research Publishing All rights reserved.

\begin{abstract}
Indacaterol is a recent ultra-long-acting inhaled $\beta_{2}$-agonist bronchodilator. The current work validated an in-house developed high performance liquid chromatography (HPLC)-tandem mass spectrometry (MS/MS) bioassay for indacaterol in human plasma. Ethyl acetate was used in a liquid-liquid extraction (LLE) method to extract indacaterol from plasma samples. A $200 \mu \mathrm{L}$ of the mobile phase (water-methanol $(30: 70, \mathrm{v} / \mathrm{v})$ ) was used to reconstitute the indacaterol dry extract. A $5 \mu \mathrm{L}$ was then eluted on a C18 column at a mobile phase flow of $1 \mathrm{~mL} / \mathrm{min}$. Formoterol was the internal standard (IS). The MS/MS was the detector. Method validation followed the International Guidelines. Indacaterol and IS were detected at a mass to charge ratio of 393.3 and 345.2, respectively. Validated calibration curves were linear over $0.075-100 \mathrm{ng} / \mathrm{mL}$. Method specificity was established in 8 different plasma batches. No matrix effect was observed. The intra-batch accuracy (precision) percentages for the lower limit of quantitation (LLOQ), Low, Mid and High quality control levels were 113.6 (10.8), 104.7 (9.1), 99.8 (7.6) and 102.2 (8.5), respectively. The inter-batch accuracy, recovery, short-term and long-term stability results were accepted. Validation has confirmed a specific, accurate and precise HPLC-MS/MS coupled with a simple and fast LLE for indacaterol in human plasma.
\end{abstract}

Keywords HPLC-MS/MS, Plasma, Validation, Liquid-Liquid Extraction, Indacaterol

\section{Introduction}

The availability of well-developed and validated bio-analytical methods for the quantitation of drugs in various human body fluids supports the conduct of research studies of various purposes including pharmacokinetic, bioequivalence and therapeutic monitoring research. Indacaterol is the first ultra-long-acting $\beta_{2}$-agonist bronchodilator that has been approved by the U.S. Food and Drug Administration (FDA) in July $2011[1,2]$. It is administered as an orally inhaled dry powder through a pre-metered, single-unit-dose capsule-based dry powder inhaler (DPI) [3,4]. Determination of the lung deposition of inhaled therapies can have many applications including studying the pharmacokinetic performance of the drugs themselves, comparing the inhaled products; especially generic against innovator or different inhaler devices, as well as comparing the inhalation techniques and flow rates used by the patients through an inhaler. Consequently, different pharmacokinetic methods have been published in the literature. These methods were based on bio-analytical techniques that determined the inhaled drug concentration in either human plasma [5-7] or urine [8-11] samples.

Recently, our research group have developed and validated a bio-analytical assay that determined indacaterol in human urine [12]. To the best of our knowledge, one work had described the validation of a bioassay for indacaterol in human serum [13]. However, that work used a sophisticated extraction technique; solid-phase extraction (SPE), that was on-line coupled to the high performance liquid chromatography-tandem mass spectrometry detection (HPLC-MS/MS) instrumentation. This on-line SPE set-up may not be available widely in the laboratories for other researchers to reproduce that analytical technique in their research studies. Therefore, we aimed in our present work to validate an in-house developed HPLC-MS/MS analytical method that involved a simple and fast liquid-liquid extraction (LLE) technique for the determination of indacaterol in human plasma. We have followed a consensus of the U.S. FDA [14] and the European Medicines Agency (EMA) [15] Guidelines 
on Bio-analytical Method Validation.

\section{Materials and Methods}

\section{Standards and Chemical Reagents}

Indacaterol maleate, $\mathrm{C}_{24} \mathrm{H}_{28} \mathrm{~N}_{2} \mathrm{O}_{3} \cdot \mathrm{C}_{4} \mathrm{H}_{4} \mathrm{O}_{4}$, molecular weight 508.6 as a maleate salt (392.49 as a base), was the reference standard (analyte) of the study. Its approximate water solubility, $\log \mathrm{P}, \mathrm{pKa}$ (strongest acidic) and $\mathrm{pKa}$ (strongest basic) are $7.9 \times 10^{-3} \mathrm{~g} / \mathrm{L}, 4.0,8.5$ and 9.8 , respectively. It was synthesized by Novartis Pharma (Batch No. 0323006) and was obtained through the Jordan Food and Drug Administration (JFDA), Amman, Jordan. The internal standard (IS) was formoterol fumarate dihydrate, $\left(\mathrm{C}_{19} \mathrm{H}_{24} \mathrm{~N}_{2} \mathrm{O}_{4}\right)_{2} \cdot \mathrm{C}_{4} \mathrm{H}_{4} \mathrm{O}_{4} \cdot\left(\mathrm{H}_{2} \mathrm{O}\right)_{2}$, molecular weight 840.92 as salt (344.405 as base), Astra Zeneca Limited (Batch No. 11401). Its approximate water solubility, $\log \mathrm{P}, \mathrm{pKa}$ (strongest acidic) and $\mathrm{pKa}$ (strongest basic) are $4.2 \times 10^{-2} \mathrm{~g} / \mathrm{L}, 1.9,8.6$ and 9.8 , respectively. The used chemical solvents and reagents were of an HPLC analytical grade. Methanol and formic acid were obtained from Merck, Germany. Ethyl acetate was obtained from Tidia, USA. Water was deionised and purified using the Milli-Q gradient system from Millipore, MA, USA. The blank human plasma batches were obtained free-of-charge from the Jordan National Blood Bank, Amman, Jordan. These were different batches that were donated by anonymous, healthy adult subjects.

\section{Instrumentation}

The HPLC system consisted of Agilent 1200 series HPLC isocratic pump, Agilent 1260 series in-line degasser, Agilent 1200 series auto-sampler, Agilent 1200 series column oven, USA. The HPLC analytical column was a Reprosil $100 \mathrm{C} 18$ $(150 \times 4.6 \mathrm{~mm}, 5 \mu \mathrm{m})$, USA. The mass spectrometric detection was performed using Applied BioSystem API 4000 Triple Quadrupole tandem mass spectrometer detector, MDS Sciex, Canada, which was equipped with a turbo $\mathrm{V}$ ion spray source in a positive mode. Nitrogen gas $(99.99 \%)$ was used (Peak nitrogen generator, Scotland). The ion source gas 1, ion source gas 2, collision gas and curtain gas were set at 50, 50, 10 and 25 psi, respectively. The ion spray voltage was set at $5500 \mathrm{~V}$. The entrance and declustering potentials were $10 \mathrm{~V}$ and $70 \mathrm{~V}$, respectively. The interface heater was set at $600{ }^{\circ} \mathrm{C}$. The collision energies for indacaterol and IS were $33.5 \mathrm{~V}$ and $29 \mathrm{~V}$, respectively. Multiple reactions monitoring (MRM) was the scanning detection mode. The acquisition of data was performed with a dwell time of $200 \mathrm{~ms}$ for each transition. The predominant indacaterol precursor ion was the protonated species $[\mathrm{H}+\mathrm{H}]^{+}$. The monitored transitions used for indacaterol $(\mathrm{m} / \mathrm{z})$ were Q1: $393.3 \rightarrow$ Q3: 173.2; and for the IS $(\mathrm{m} / \mathrm{z})$ were Q1: $345.2 \rightarrow$ Q3: 149.1. Other used instruments were an analytical balance Mettler Toledo XP2U (Switzerland), a pH meter Mettler Toledo (Switzerland), Centrifuge Eppendorf 5810R (Germany) and Vortex IKA ${ }^{\circledR}$ VX1 (Germany). Gilson micropipettes, France, were used.

The processing of the chromatograms, calibration curves and regression calculations was performed by the Analyst ${ }^{\circledR} 1.6$ software (MDS Sciex, Canada). The management of the acquired data was also done using Watson Thermo Quest Lab Management system $\left(\mathrm{LMS}^{\circledR}\right)$.

\section{Preparation of Indacaterol and IS Stock and Working Solutions}

An indacaterol stock solution was prepared by dissolving indacaterol maleate salt in methanol to give a final stock concentration equivalent to $500 \mu \mathrm{g} / \mathrm{mL}$ of indacaterol free base. A volume of $100 \mu \mathrm{L}$ of this stock solution was then diluted with methanol in a $25 \mathrm{~mL}$ volumetric flask to give a $2 \mu \mathrm{g} / \mathrm{mL}$ indacaterol working solution. In the same manner, the IS stock and working solutions were prepared to give final concentrations of $500 \mu \mathrm{g} / \mathrm{mL}$ and $2 \mu \mathrm{g} / \mathrm{mL}$ of formoterol free base, respectively.

\section{Preparation of Standard Calibration Curve Points}

Nine serial dilutions to the indacaterol working solution in a diluent solvent of water/methanol $(50 / 50 \mathrm{v} / \mathrm{v})$ mixture were performed to give indacaterol concentrations of $0.75,1.0,2.0$, $10.0,50.0,100.0,400.0,800.0$ and $1000 \mathrm{ng} / \mathrm{mL}$. Then, a volume of $500 \mu \mathrm{L}$ of each of these solutions was used to spike a blank human plasma to give the following nine standard calibration curve points with final concentrations of $0.075,0.10,0.20,1.0,5.0,10.0,40.0,80.0$ and 100 $\mathrm{ng} / \mathrm{mL}$.

\section{Preparation of Quality Control (QC) Points}

Three serial dilutions to the indacaterol working solution in a diluent mixture of water/methanol $(50 / 50 \mathrm{v} / \mathrm{v})$ were performed to give indacaterol concentrations of $2.25,500$ and $850 \mathrm{ng} / \mathrm{mL}$. Then, a volume of $500 \mu \mathrm{L}$ of each of these solutions was used to spike a blank human plasma to give the following three QC points with final concentrations of 0.225 , 50.0 and $85.0 \mathrm{ng} / \mathrm{mL}$.

Additionally, a $500 \mu \mathrm{L}$ of the indacaterol working solution was diluted up to $5 \mathrm{~mL}$ with blank plasma to give a final concentration of $200 \mathrm{ng} / \mathrm{mL}$ which was used specifically as a QC solution for the dilution integrity validation test.

\section{Sample Preparation and Extraction Method}

The sample preparation and LLE procedure for indacaterol and IS from the human plasma is presented in Table 1. In addition to the 9 non-zero calibration curve points, a blank sample and a zero sample were also included in the calibration curve. The blank sample was a plasma sample that was prepared and extracted without being spiked with indacaterol and IS. The zero sample was a plasma sample that was prepared and extracted without being spiked with indacaterol. The procedure in Table 1 was followed to prepare and extract the blank samples, however without performing steps 3 and 4 . Instead, the blank samples were spiked with $50 \mu \mathrm{L}$ of methanol (step 6) to compensate for the $50 \mu \mathrm{L}$ volume of the IS. The same procedure was followed to prepare and extract the zero samples, however without performing step 3 . 
Table 1. Sample Preparation and LLE Procedure of Indacaterol and IS from Human Plasma.

\begin{tabular}{|c|r|}
\hline 1. & Pipette $1 \mathrm{~mL}$ of blank human plasma into a $10 \mathrm{~mL}$ test tube. \\
\hline 2. & Take the blank sample apart. \\
\hline 3. & $\begin{array}{r}\text { Spike each sample (non-blank and non-zero) with a certain volume of indacaterol working standard solutions, as appropriate, to get a } \\
\text { concentration equivalent to LLOQ, Low, Mid or High QC level according to the validation test being performed. }\end{array}$ \\
\hline 4. & Spike each sample with $50 \mu \mathrm{L}$ IS working solution. \\
\hline 5. & Add $400 \mu \mathrm{L}$ of $25 \%$ formic acid. \\
\hline 6. & Spike the blank sample with $50 \mu \mathrm{L}$ of methanol to compensate for the $50 \mu \mathrm{L}$ of IS solution used for spiking the other samples. \\
\hline 7. & Add $4 \mathrm{~mL}$ of ethyl acetate (the extraction solvent) and vortex for 60 seconds. \\
\hline 8. & Centrifuge for 5 minutes at a speed of 4000 rpm at $5{ }^{\circ} \mathrm{C}$. \\
\hline 9. & Freeze the sample and decant the upper organic layer into a new test tube. \\
\hline 10. & Evaporate the organic layer under a nitrogen stream at $40{ }^{\circ} \mathrm{C}$. \\
\hline 11. & Reconstitute the dry residue with $200 \mu \mathrm{L}$ of the mobile phase. \\
\hline 12. & Inject $5 \mu \mathrm{L}$ directly into the LC-MS/MS system using the auto-sampler kept at $5{ }^{\circ} \mathrm{C}$. \\
\hline
\end{tabular}

\section{HPLC-MS/MS Analytical Method}

A volume of $5 \mu \mathrm{L}$ of the extracted samples was injected, via the auto-sampler (kept at $5{ }^{\circ} \mathrm{C}$ ), into the HPLC-MS/MS system for analysis. The samples were analysed on a reversed-stationary phase using a Reprosil $100 \mathrm{C} 18(150 \times 4.6$ $\mathrm{mm}, 5 \mu \mathrm{m})$ column at a temperature of $40{ }^{\circ} \mathrm{C}$. The mobile phase consisted of a mixture of deionized water and methanol $(30: 70(\mathrm{v} / \mathrm{v}))$ acidified with $300 \mu \mathrm{L}$ of formic acid per litre of the mixture. An isocratic elution was used at a flow rate of 1 $\mathrm{mL} / \mathrm{min}$ with a total analytical run-time of 3 minutes. The retention times $\left(\mathrm{t}_{\mathrm{R}}\right)$ of indacaterol and IS were 2.5 and 1.5 minutes, respectively.

\section{Method Validation}

A consensus of the U.S. FDA[14] and the European Medicines Agency [15] (EMA) Bioanalytical Method Validation Guidelines was followed.

\section{Calibration Curve Linearity and Lower Limit of Quantitation (LLOQ)}

Initially, the lower limit of detection (LOD), the lowest concentration of indacaterol that the bioanalytical procedure can reliably differentiate from the background noise, was determined. This LOD was differentiated from the LLOQ which was the lowest amount of indacaterol in a sample that could be quantitatively determined with acceptable precision and accuracy. Then to validate the method's calibration curve, six different calibration curves were analysed on six different days to check for linearity and accuracy. The peak-area ratios (peak area of indacaterol to peak area of IS) on $y$-axis vs the calibration curve points concentrations on $x$-axis were plotted and fitted to the equation; $y=\mathrm{b} x+\mathrm{a}$, where (a) represents the $y$-axis intercept and (b) represents the slope. The $1 / x$ weighting was used for linearity fitting. The acceptance criteria included not more than $\pm 20 \%$ deviation at LLOQ $( \pm 15 \%$ at other points $)$ from nominal concentrations. At least $75 \%$ of non-zero standards should meet the above criteria including the LLOQ and the upper LOQ (ULOQ) with an overall correlation coefficient $(r) \geq 0.95$.

The sample dilution integrity was assessed where six two-fold the ULOQ samples were prepared and then diluted four times with a blank human plasma to get a mid-range calibration curve concentration. These diluted samples were then extracted and analysed. An accuracy of $\pm 15 \%$ and a precision $<15 \%$ were the test acceptance criteria.

\section{Intra-Batch and Inter-Batch Accuracy and Precision}

The intra-batch accuracy and precision were investigated by analysing six replicate samples at four different indacaterol concentrations (ng/mL); 0.075 (LLOQ), 0.225 (Low QC), 50.0 (Mid QC) and 85.0 (High QC) which were prepared from the same plasma batch and analysed on the same day. The inter-batch accuracy and precision were evaluated by analysing six replicate samples at each of the previous concentration levels prepared from 3 different plasma batches and analysed on 3 different days. The accuracy at each concentration level was the ratio of the actual to nominal concentrations. The deviation of the mean from the true value was used as an accuracy measure. The precision was the ratio of standard deviation to mean $(\% \mathrm{CV})$. The acceptance criteria were mean accuracy within $\pm 20 \%$ at the LLOQ level $( \pm 15 \%$ at other QC levels) and precision of $<20 \%$ at the LLOQ ( $<15 \%$ at other QC levels).

\section{Specificity}

The specificity of the bioanalytical method was evaluated by screening six different batches of human plasma to ensure that the analytical response of the LLOQ prepared samples was at least five times the response of the blank samples at the $t_{R}$ of indacaterol, and to ensure that the analytical response in each corresponding blank sample at the $t_{R}$ of the IS was less than $5 \%$ of that of the IS spiked sample (zero sample). Moreover, the specificity was studied in two additional batches of lipemic and hemolyzed plasma samples. 


\section{Matrix Effect}

Plasma matrix interference was investigated by comparing the analytical response (peak areas) of six low QC-equivalent standard working solutions (SET 1) with that of low QC samples prepared and extracted from six different plasma batches (SET 2). Two additional batches of lipemic and hemolyzed plasma batches were also assessed. The matrix factors (MF) were calculated for both indacaterol and IS for each plasma batch by dividing each peak area of the post-extracted spiked samples in SET 2 by the corresponding mean peak areas of SET 1 and then multiplied by 100 . The IS-normalized MF was then calculated by dividing the MF of indacaterol by the MF of IS for each plasma batch. To have no matrix effect, the $\% \mathrm{CV}$ of the IS-normalized MF should be $<15 \%$.

\section{Carryover}

The carryover was assessed by injecting a blank sample immediately after the end of the third inter-batch accuracy and precision validation test (to cover the maximum number of samples of the batch). To have no carryover effect, the peak areas of the blank sample at the $t_{R}$ of indacaterol and IS should be $<20 \%$ of the peak area observed for indacaterol at the LLOQ level and $<5 \%$ of the response observed for the IS.

\section{Recovery}

The recovery of indacaterol was examined at the Low QC, Mid QC and High QC levels. The recovery of the IS was evaluated at a concentration of $200 \mathrm{ng} / \mathrm{mL}$. Using one plasma batch, two sets of samples (6 replicates each) were prepared at each of the three QC levels (named SET 1 and SET 2). For SET 1, the six samples of blank plasma were extracted first according to the extraction method and were then spiked with the appropriate indacaterol standard solution to get the required QC level.

For SET 2, the six samples of blank plasma were spiked first with the appropriate indacaterol standard solution corresponding to the required $\mathrm{QC}$ level and were then extracted as per the extraction procedure. SET 1 and SET 2 were then analysed. The peak areas of the IS were also evaluated in both sets at the Mid concentration level. At each QC level, the recovery \% was calculated by dividing the peak area of each run of SET 2 by the mean of the peak areas of SET 1 multiplied by 100 . The recovery was accepted if the precision $(\% \mathrm{CV})$ at each QC level was $\leq 15 \%$.

\section{Stability}

Sufficient volumes of six replicate samples of the Low QC and High QC levels were prepared and immediately analysed to evaluate the initial stability. Then, the remaining volumes were frozen immediately at $-70{ }^{\circ} \mathrm{C}$ to be analysed later to evaluate the short-term, long-term and freeze-thaw stabilities of the samples, as follows. The stability acceptance criteria were an accuracy between $85-115 \%( \pm 15 \%)$ and a precision $(\% \mathrm{CV})<15 \%$.

\section{Short-Term and Long-Term Stabilities}

The short-term stability samples were frozen at $-70{ }^{\circ} \mathrm{C}$ for about two hours (until completely frozen) and were then left at room temperature (RT) for around 24 hours. After that these samples were extracted and analysed along with freshly prepared calibration curve points and two fresh replicate samples at each QC level. The long-term stability was investigated in a similar manner; however the samples were frozen at $-70{ }^{\circ} \mathrm{C}$ for 60 days before being thawed unassisted at RT, extracted and analysed.

To check for the calibration curve stability, sufficient volumes of the calibration curve points were prepared and analysed immediately for the initial stability evaluation. Additional calibration curve points were prepared and stored at $-70{ }^{\circ} \mathrm{C}$ for 60 days. After which they were analysed to test their long-term stability.

\section{Freeze-Thaw Stability}

The stability of the spiked plasma samples was investigated after three freeze-thaw cycles. Each cycle included freezing the samples at $-70{ }^{\circ} \mathrm{C}$ for 24 hours followed by unassisted thawing at RT. At the end of the third freeze-thaw cycle, the plasma samples were extracted and then analysed simultaneously with freshly prepared calibration curve points and two fresh replicate samples at each QC level.

\section{Auto-Sampler Stability}

Six replicate samples of the Low, Mid and High QC levels were prepared, extracted and analysed initially with a freshly prepared standard calibration curve on the same batch (run). The whole batch was re-analysed after being stored in the auto-sampler at $5^{\circ} \mathrm{C}$ for 24 hours. The auto-sampler stability was evaluated using two approaches; the post-preparative stability (PPS) approach where the re-injected QC samples were back-calculated using the initial calibration curve. Whilst, the second approach was the processed samples integrity (PSI) where the re-injected QC samples where back-calculated using the re-injected calibration curve.

\section{Dry-Extract Stability}

Six replicate samples of the Low, Mid and High QC levels were prepared and extracted. However, before the reconstitution step, the samples were stored as dry residues at $-70{ }^{\circ} \mathrm{C}$ for 24 hours. The samples were then reconstituted with $200 \mu \mathrm{L}$ of the mobile phase and analysed simultaneously with a freshly prepared calibration curve.

\section{Stock and Working Solutions Stability}

The stability of the stock and working standard solutions of indacaterol and IS after being stored at RT for six hours and after being stored at $-70{ }^{\circ} \mathrm{C}$ for eight days was investigated and confirmed in a previous work of ours [12].

\section{Results}




\section{Calibration Curve}

Table 2 presents the mean accuracy, the precision and the linearity function parameters of the six validated calibration curves along with their regression coefficients (r). The calibration curves were linear over the range of $0.075-100$ $\mathrm{ng} / \mathrm{mL}$. The lower limit of detection (LOD) of indacaterol in plasma was $0.050 \mathrm{ng} / \mathrm{mL}$. However, the LLOQ was identifiable and reproducible at $0.075 \mathrm{ng} / \mathrm{mL}$ with a mean accuracy of $99.56 \%$ and a precision of $13.0 \%$. Moreover, the sample dilution integrity results met the acceptance criteria. The accuracy and precision were $94.3 \%$ and $9.3 \%$, respectively.

\section{Accuracy and Precision}

The intra-batch accuracy and precision results for the LLOQ, Low, Mid and High QC levels met the acceptance criteria. The accuracy (precision) percentages were 113.6 (10.8), 104.7 (9.1), 99.8 (7.6) and 102.2 (8.5) for these levels, respectively. Figures $1-4$ are examples on representative chromatograms for the LLOQ, Low, Mid and High QC levels, respectively. Table 3 presents the inter-batch accuracy and precision results for three human plasma batches which met the acceptance criteria.

Table 2. Accuracy, precision and linearity functions of the calibration curves

\begin{tabular}{|c|c|c|c|c|c|c|c|c|c|c|}
\hline \multirow[b]{2}{*}{$\begin{array}{c}\text { Concentration } \\
\mathrm{ng} / \mathrm{mL}\end{array}$} & Nominal & 0.075 & 0.10 & 0.20 & 1.0 & 5.0 & 10.0 & 40.0 & 80.0 & 100.0 \\
\hline & $\begin{array}{c}\text { Mean (SD) } \\
\text { Back-calculated } \\
(\mathrm{n}=6 \text { curves })\end{array}$ & $\begin{array}{c}0.075 \\
(0.010)\end{array}$ & $\begin{array}{c}0.105 \\
(0.006)\end{array}$ & $\begin{array}{c}0.194 \\
(0.014)\end{array}$ & $\begin{array}{c}0.936 \\
(0.069)\end{array}$ & $\begin{array}{c}5.085 \\
(0.306)\end{array}$ & $\begin{array}{c}9.970 \\
(0.721)\end{array}$ & $\begin{array}{l}42.390 \\
(1.260)\end{array}$ & $\begin{array}{l}80.832 \\
(2.968)\end{array}$ & $\begin{array}{l}96.764 \\
(4.143)\end{array}$ \\
\hline \multicolumn{2}{|c|}{ Mean accuracy $(\%)$} & 99.56 & 105.33 & 96.83 & 93.60 & 101.71 & 99.70 & 105.98 & 101.04 & 96.77 \\
\hline \multicolumn{2}{|c|}{ Mean precision $(\%)$} & 13.00 & 5.72 & 7.43 & 7.43 & 6.02 & 7.23 & 2.97 & 3.67 & 4.28 \\
\hline \multicolumn{11}{|c|}{ Parameters of the calibration curves functions; $y=\mathrm{b} x+\mathrm{a}$} \\
\hline & Curve 1 & \multicolumn{2}{|c|}{ Curve 2} & \multicolumn{2}{|c|}{ Curve 3} & \multicolumn{2}{|c|}{ Curve 4} & Curve 5 & \multicolumn{2}{|c|}{ Curve 6} \\
\hline$a^{*}$ & $9.50 \times 10^{-05}$ & \multicolumn{2}{|c|}{$1.83 \times 10^{-04}$} & \multicolumn{2}{|c|}{$2.85 \times 10^{-04}$} & \multicolumn{2}{|c|}{$8.40 \times 10^{-05}$} & $3.25 \times 10^{-0}$ & \multicolumn{2}{|c|}{$-2.00 \times 10^{-05}$} \\
\hline $\mathrm{b}^{* *}$ & $7.89 \times 10^{-03}$ & \multicolumn{2}{|c|}{$8.12 \times 10^{-03}$} & \multicolumn{2}{|c|}{$7.60 \times 10^{-03}$} & \multicolumn{2}{|c|}{$7.50 \times 10^{-03}$} & $9.19 \times 10^{-0}$ & \multicolumn{2}{|c|}{$3.52 \times 10^{-03}$} \\
\hline $\mathrm{r}^{* * *}$ & 0.9986 & \multicolumn{2}{|c|}{0.9953} & \multicolumn{2}{|c|}{0.9999} & \multicolumn{2}{|c|}{0.9993} & 0.9993 & \multicolumn{2}{|c|}{0.9998} \\
\hline
\end{tabular}

* a: Calibration curve y-axis intercept. **b: Calibration curve slope. $\quad * * *$ r: Calibration curve regression factor.

Table 3. The inter-batch accuracy and precision results for indacaterol in plasma.

\begin{tabular}{|c|c|c|c|c|}
\hline & $\begin{array}{c}\text { LLOQ }^{\mathrm{a}} \\
(0.075 \mathrm{ng} / \mathrm{mL})\end{array}$ & $\begin{array}{c}\text { Low QC }^{\mathrm{b}} \\
(0.225 \mathrm{ng} / \mathrm{mL})\end{array}$ & $\begin{array}{c}\text { Mid QC }^{\mathrm{b}} \\
(50 \mathrm{ng} / \mathrm{mL})\end{array}$ & $\begin{array}{c}\text { High QC }^{\mathrm{b}} \\
(85 \mathrm{ng} / \mathrm{mL})\end{array}$ \\
\hline Mean $^{\mathrm{c}}$ & 0.081 & 0.229 & 49.941 & 86.782 \\
\hline SD & 0.012 & 0.023 & 4.97 & 6.259 \\
\hline $\begin{array}{c}\text { Precision } \\
\text { (CV\%) }\end{array}$ & 14.37 & 10.16 & 99.88 & 7.21 \\
\hline $\begin{array}{c}\text { Accuracy } \\
(\%)\end{array}$ & 107.85 & 101.80 & 92.10 \\
\hline
\end{tabular}

a: Lower limit of quantitation. $\quad$ b: Quality control level. c: Mean indacaterol concentrations, $\mathrm{ng} / \mathrm{mL}$ ( $\mathrm{n}=3$ plasma batches).

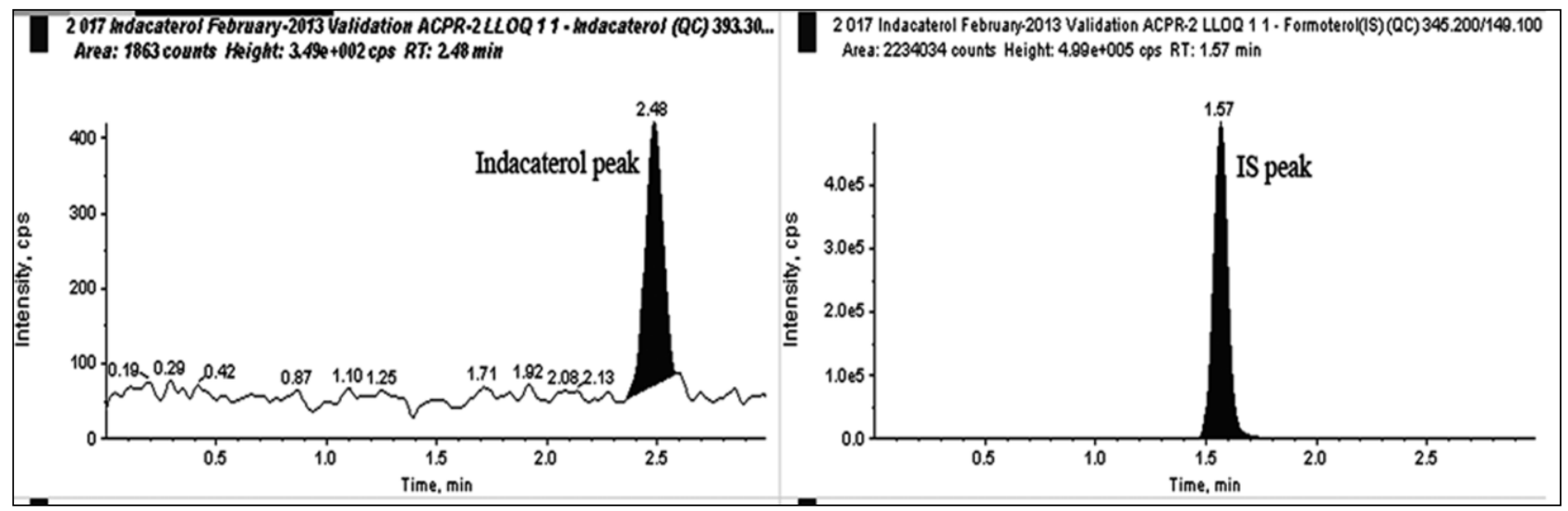

Figure 1. Representative chromatogram at LLOQ - Indacaterol (left) and IS (right). 


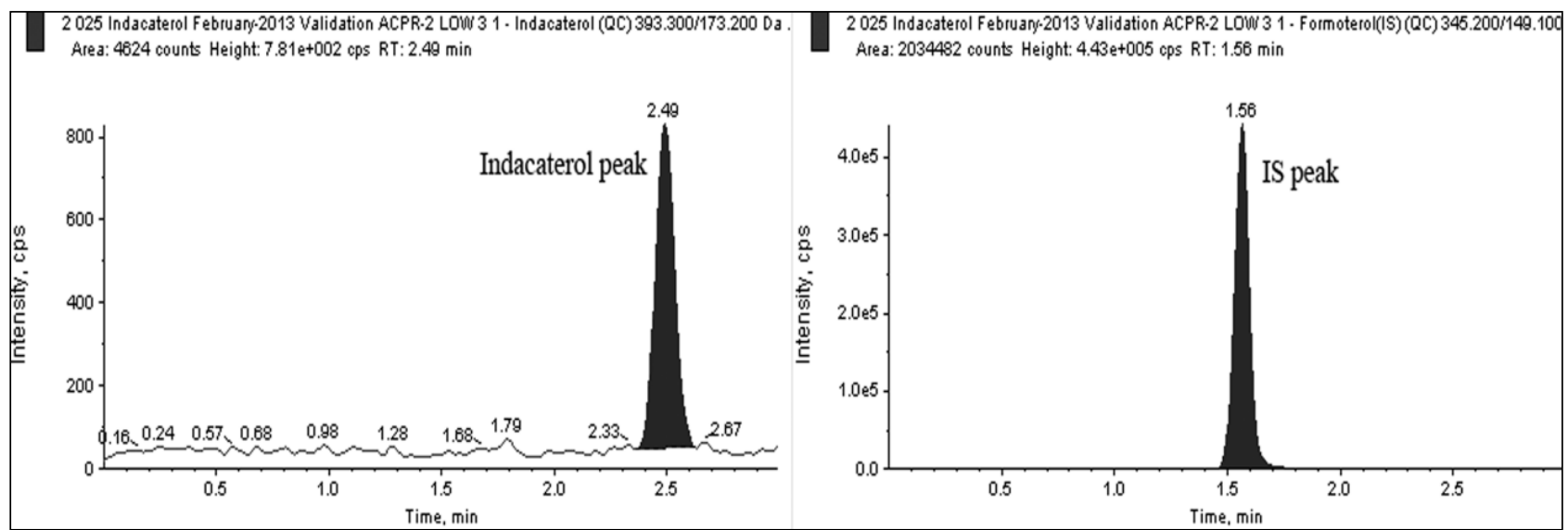

Figure 2. Representative chromatogram at Low QC - Indacaterol (left) and IS (right).

2031 indacaterol February-2013 Validation ACPR-2 MOD 31 - hndacaterol (QC) 393.300/... Ares: 890953 counts Height: $1.540+005$ cps $R T: 248 \mathrm{~min}$

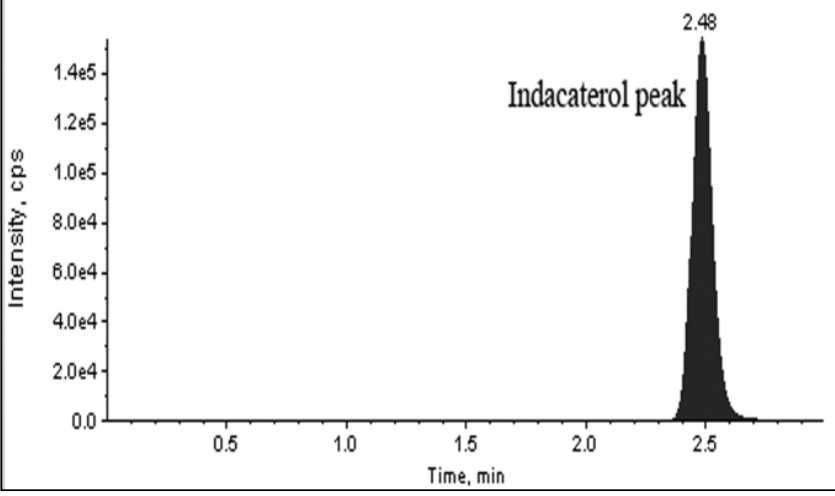

2031 Indacaterol Februany-2013 Validation ACPR.2 MID 31 - Formoterol(IS)(QC) $345.200 / 149.100 \mathrm{D}$ Area: 2179331 counts Height: $4.79 \mathrm{e}+005 \mathrm{cps}$ RT: 1.57 min

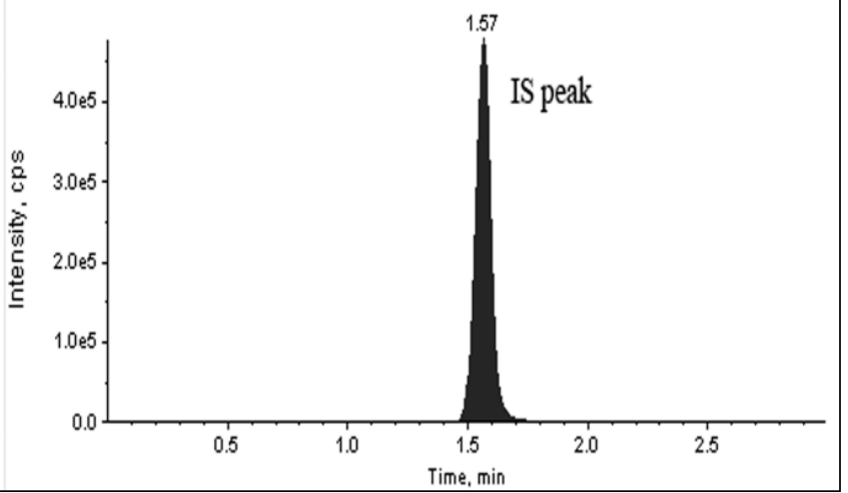

Figure 3. Representative chromatogram at Mid QC - Indacaterol (left) and IS (right).

2035 indacaterol February-2013 Validation ACPR-2 HIIGH 11 - indacaterol (QC) 393.300\%... Ares: 1372420 counts Height: $237 \mathrm{e}+005 \mathrm{cps}$ RT: $247 \mathrm{~min}$

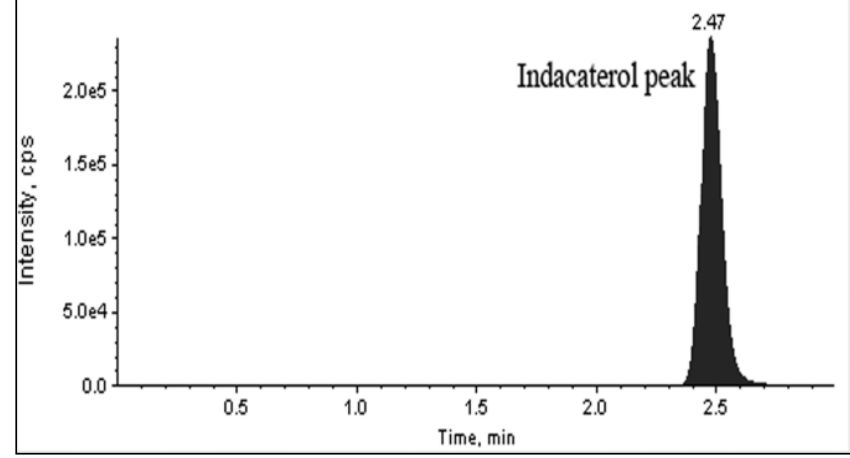

2035 Indacaterol February-2013 Validation ACPR.2 HIGH 11 - Formoterol(IS)(QC) $345.200 / 149.100$ Area: 1873538 counts Height: $4.04 \mathrm{e}+005 \mathrm{cps}$ RT: $1.56 \mathrm{~min}$

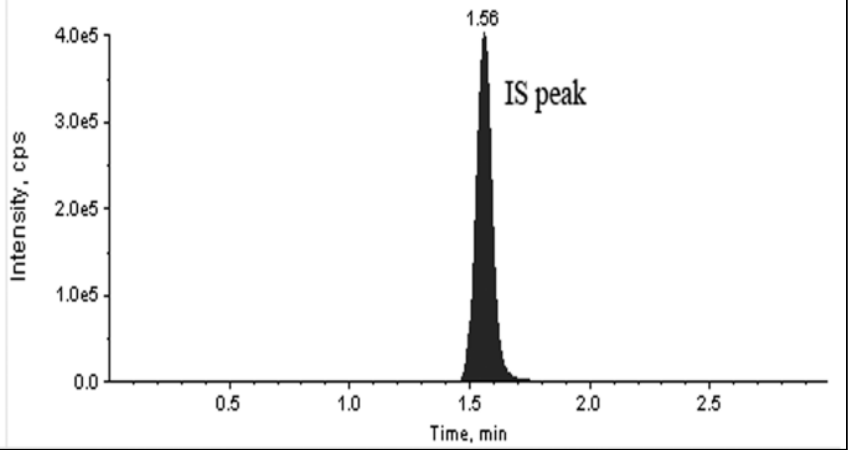

Figure 4. Representative chromatogram at High QC - Indacaterol (left) and IS (right) 


\section{Specificity}

No interfering peaks were observed at the $t_{R}$ of both indacaterol (around 2.50 minutes) and IS (around 1.50 minutes) in the chromatograms of the eight analysed plasma batches. Therefore, the ratios of the peak areas of indacaterol and IS in each LLOQ sample of the eight validated plasma batches to their corresponding peak areas (not observed) in each blank sample were zero (acceptance $<5 \%$ ). This confirms that our method is specific for both indacaterol and IS quantification in human plasma.

\section{Matrix Effect}

The results of the matrix effect are shown in Table 4 . Plasma had no interfering effect on the determination of both indacaterol and the IS in the current analytical method.

\section{Carryover}

The carryover results showed that the ratio of the peak area at the $t_{R}$ of indacaterol in the blank sample to the peak area of indacaterol in the spiked LLOQ sample was zero (acceptance $<20 \%$ ). Similarly, no peak was observed for the IS in the blank sample, therefore the ratio was also zero for the IS carryover assessment (acceptance $<5 \%$ ).

\section{Recovery}

The mean recovery (precision) percentages of indacaterol from plasma at the Low, Mid and High QC levels were 55.41 (14.99), 54.32 (14.96) and 54.70 (6.35), respectively. The mean recovery (precision) percentage of the IS was 48.92
(13.22). The recovery of indacaterol and IS from plasma was consistent, precise and reproducible.

\section{Short-Term, Long-Term and Freeze-Thaw Stabilities}

Table 5 presents the results of the freshly-prepared (initial), short-term, long-term and freeze-thaw stability of indacaterol in human plasma. The long-term stability results of the calibration curve points showed an accuracy range between 91.66 and $104.55 \%$. The calibration curve had an equation; $y$ $=0.0035 x-7.80 \times 10^{-5}$, and $r$ value of 0.9996 . The stability evaluation met the acceptance criteria.

\section{Auto-Sampler Stability}

The PPS results at the Low, Mid and High QC levels showed mean accuracy (precision) percentages of 109.82 (9.93), 106.46 (1.90) and 107.04 (1.69), respectively. The PSI mean accuracy (precision) percentages were 102.31 (8.96), 100.17 (1.83) and 100.56 (1.69) at the corresponding QC levels, respectively. These results confirm that the indacaterol samples were stable in the auto-sampler at $5{ }^{\circ} \mathrm{C}$ for 24 hours.

\section{Dry-Extract Stability}

The mean accuracy (precision) percentages for the indacaterol dry extract at the Low, Mid and High QC levels were 107.78 (5.80), $112.26(8.03)$ and 107.45 (7.42), respectively. These results indicated that the dry extract of indacaterol was stable at $-70{ }^{\circ} \mathrm{C}$ for 24 hours before being reconstituted for analysis.

Table 4. The matrix effect results for indacaterol and IS determination in plasma.

\begin{tabular}{|c|c|c|c|c|c|c|c|}
\hline & \multicolumn{2}{|c|}{$\begin{array}{c}\text { HPLC-MS/MS } \\
\text { peak area for indacaterol }\end{array}$} & \multirow{2}{*}{$\begin{array}{c}\mathrm{MF}^{\mathrm{a}} \\
\text { (Indacaterol) }\end{array}$} & \multicolumn{2}{|c|}{$\begin{array}{c}\text { HPLC-MS/MS } \\
\text { peak area for IS }\end{array}$} & \multirow{2}{*}{$\mathrm{MF}^{\mathrm{a}}$ (IS) } & \multirow{2}{*}{$\begin{array}{c}\mathrm{IS}^{\mathrm{b}}- \\
\text { normalize } \\
\mathrm{MF}^{\mathrm{a}}\end{array}$} \\
\hline & SET 1 & SET 2 & & SET 1 & SET 2 & & \\
\hline Mean $(n=8)$ & $7.057 \times 10^{3}$ & $6.954 \times 10^{3}$ & 98.539 & $3.347 \times 10^{6}$ & $3.846 \times 10^{6}$ & 114.926 & 0.857 \\
\hline SD & $3.581 \times 10^{2}$ & $4.438 \times 10^{2}$ & 6.289 & $8.736 \times 10^{4}$ & $1.462 \times 10^{5}$ & 4.367 & 0.040 \\
\hline CV\% & 5.07 & 6.38 & 6.382 & 2.61 & 3.80 & 3.800 & 4.611 \\
\hline
\end{tabular}

a: Matrix factor. b: Internal standard.

Table 5. The initial, short-term, long-term and freeze-thaw stability results of indacaterol in plasma

\begin{tabular}{|c|c|c|c|c|c|c|c|c|}
\hline & \multicolumn{2}{|c|}{$\begin{array}{c}\text { Initial stability of indacaterol } \\
\text { in plasma }\end{array}$} & $\begin{array}{c}\text { Short-term stability at RT } \\
\text { for 24 hours }\end{array}$ & \multicolumn{2}{c|}{$\begin{array}{c}\text { Long-term stability at } \\
-70^{\circ} \mathrm{C} \text { for } 60 \text { days }\end{array}$} & \multicolumn{2}{c|}{ Freeze-thaw stability } \\
\cline { 2 - 9 } & Low QC & High QC & Low QC & High QC & Low QC & High QC & Low QC & High QC \\
\hline Mean $^{\mathrm{a}}$ & 0.236 & 86.907 & 0.247 & 96.901 & 0.235 & 86.366 & 0.241 & 95.255 \\
\hline SD & 0.022 & 7.392 & 0.029 & 3.200 & 0.024 & 2.803 & 0.033 & 9.092 \\
\hline $\begin{array}{c}\text { Precision } \\
\text { (CV\%) }\end{array}$ & 9.15 & 8.51 & 11.62 & 3.30 & 10.30 & 3.25 & 13.61 & 9.54 \\
\hline Accuracy (\%) & 104.74 & 102.24 & 109.56 & 114.00 & 104.44 & 101.61 & 107.04 & 112.06 \\
\hline
\end{tabular}

a: Mean indacaterol concentrations, $\mathrm{ng} / \mathrm{mL}(\mathrm{n}=6) . \quad \mathrm{b}$ : Room temperature. 


\section{Discussion}

In the current work, a simple liquid-liquid extraction method was developed to extract indacaterol from a $1 \mathrm{~mL}$ sample of human plasma. The extraction solvent was a $4 \mathrm{~mL}$ of ethyl acetate (acidified with $400 \mu \mathrm{l}$ of $25 \%$ formic acid). The indacaterol dry extract was then reconstituted with a $200 \mu \mathrm{L}$ of the mobile phase which was simply an acidified mixture of water and methanol $(30: 70, \mathrm{v} / \mathrm{v})$. After that, only $5 \mu \mathrm{L}$ injection volume was needed for the HPLC analysis that involved eluting indacaterol and formoterol IS on a reversed C18 stationary phase with an isocratic mobile phase pumped at a flow rate of $1 \mathrm{~mL} / \mathrm{min}$. The detection system involved the tandem mass spectrometer which employed turbo-ion spray ionization in the positive ion mode along with a multiple reactions monitoring (MRM). Accordingly, indacaterol was monitored at a molecular ion $\mathrm{m} / \mathrm{z}$ ratio of 393.3 and an $\mathrm{MS} / \mathrm{MS}$ daughter at $\mathrm{m} / \mathrm{z}$ ratio of 173.2 . Whilst, the IS was monitored at molecular ion $\mathrm{m} / \mathrm{z}$ ratio of 345.2 and an MS/MS daughter at $\mathrm{m} / \mathrm{z}$ ratio of 149.1 . The total analytical run-time was 3 minutes.

This developed method was then validated according to the international guidelines on bio-analytical method validation $[14,15]$. The results of the various validation measures have shown that our method was specific, accurate, precise, stable and reproducible. The linearity for indacaterol determination in plasma was confirmed over a concentration range between 0.075 and $100 \mathrm{ng} / \mathrm{mL}$ with a LLOQ of $0.075 \mathrm{ng} / \mathrm{mL}$.

One previous published work has developed and validated an HPLC-MS/MS bio-analytical method for indacaterol in human serum [13]. However, that method was fully automated with an on-line sophisticated solid-phase extraction (SPE) technique which might not be widely available in the analytical laboratories. Additionally, this solid phase extraction platform for indacaterol from serum involved two solvent-preconditioning steps for the cartridges that consumed 20 minutes, in addition to other several extraction steps with several chemical solvents needed. A labelled ${ }^{13} \mathrm{CD}_{3}$-indacaterol as an internal standard was employed in that method. Unlike the fast analytical run-time and the simple isocratic mobile phase flow of the current work, Emotte and co-workers (2012) used a gradient mobile phase flow with a total analytical run-time of 6 minutes.

However, the present work was limited by the higher indacaterol LLOQ and accordingly the quantitation range compared with the previously published one which ranged between 10 and $1000 \mathrm{pg} / \mathrm{mL}$ [13]. In this reference, indacaterol is clinically approved in 3 once-daily strengths; $75 \mathrm{mcg}$ (in USA), 150 and $300 \mathrm{mcg}$ (in Europe and many other countries) [2]. Additionally, the developmental single-dose and multiple-dose clinical pharmacokinetic studies safely used much higher indacaterol doses of up to $3000 \mathrm{mcg}$ [16]. Therefore, the ability to clinically use this wide range of indacaterol strengths safely would help overcome this study limitation, and thus allow the researchers to use both our current plasma and previous urinary [12] analytical methods in their future pharmacokinetic, bioequivalence and clinical studies of indacaterol.

\section{Conclusions}

The validation of an in-house developed simple and fast LLE coupled with an HPLC-MS/MS technique has confirmed an accurate, precise and specific determination of indacaterol in human plasma. This bioanalytical technique is robust and reproducible to support future indacaterol-related research studies.

\section{Acknowledgements}

The Authors would like to thank ACDIMA Centre for Bioequivalence and Pharmaceutical Studies, Amman, Jordan, for logistically supporting the conduct of this research by providing all the needed chemicals and instrumentation.

\section{Author Disclosure Statement}

Wesam Ammari, Zainab Al-Qadhi, Mohammad Khalil, Rabab Tayyem, Samir Qammaz, Ghaleb Oriquat and Iman A. Basheti all have no conflicts of interest.

Henry Chrystyn has no shares in any pharmaceutical companies. He has received sponsorship to carry out studies, together with some consultant agreements and honoraria for presentations, from several pharmaceutical companies that market inhaled products. These include AbdiIbrahim, Almirall, AstraZeneca, Boehringer Ingelheim, Chiesi, GlaxoSmithKline, Innovata Biomed, Meda, Mundipharma, Omron, Sandoz, Teva, Truddell, and UCB. Research sponsorship has also been received from grant awarding bodies (EPSRC and MRC).

\section{REFERENCES}

[1] S. M. Ray, J. C. McMillen, S. A. Treadway, R. S. Helmer, A. S. Franks. Indacaterol: A novel long-acting beta(2)-agonist, Pharmacotherapy. Vol.32, No.5, 456-474, 2012.

[2] B. A. Chowdhury, S. M. Seymour, T. M. Michele, A. G Durmowicz, D. M. Liu, C. J. Rosebraugh. The risks and benefits of indacaterol - the fda's review, New England Journal of Medicine. Vol.365, No.24, 2247-2249, 2011.

[3] European Medicines Agency. Human medicines: Onbrez breezhaler (indacaterol). [Accessed 15 January 2014]. Online Available from: http://www.ema.europa.eu/ema/index.jsp?curl =pages $/$ medicines $/$ human $/$ medicines $/ 001114 /$ human_med_001 219.jsp\&murl $=$ menus $/$ medicines $/$ medicines.jsp\&mi $\bar{d}=\mathrm{WC} 0 \mathrm{~b} 01$ ac058001d 124

[4] Novartis Pharma AG: Onbrez breezhaler patient information pamphlet. 2010. 
[5] B. J. Lipworth, C. M. Jackson. Pharmacokinetics of chlorofluorocarbon and hydrofluoroalkane metered-dose inhaler formulations of beclomethasone dipropionate, British Journal of Clinical Pharmacology. Vol.48, No.6, 866-868, 1999.

[6] H. Chrystyn. Methods to identify drug deposition in the lungs following inhalation, British Journal of Clinical Pharmacology. Vol.51, No.4, 289-299, 2001.

[7] D. Acerbi, G. Brambilla, I. Kottakis. Advances in asthma and COPD management: Delivering cfc-free inhaled therapy using modulite (r) technology, Pulmonary Pharmacology \& Therapeutics. Vol.20, No.3, 290-303, 2007.

[8] L. Borgstrom, M. Nilsson. A method for determination of the absolute pulmonary bioavailability of inhaled drugs terbutaline, Pharmaceutical Research. Vol.7, No.10, 1068-1070, 1990.

[9] M. Hindle, H. Chrystyn. Determination of the relative bioavailability of salbutamol to the lung following inhalation, British Journal of Clinical Pharmacology. Vol.34, No.4, 311-315, 1992.

[10] M. E. Abdelrahim, K. H. Assi, H. Chrystyn. Relative bioavailability of terbutaline to the lung following inhalation, using urinary excretion, British Journal of Clinical Pharmacology. Vol.71, No.4, 608-610, 2011.

[11] A. S. A. Said, L. P. Harding, H. Chrystyn. Urinary pharmacokinetic methodology to determine the relative lung bioavailability of inhaled beclometasone dipropionate, British Journal of Clinical Pharmacology. Vol.74, No.3, 456-464, 2012.
[12] W. G. Ammari, Z. Al-Qadhi, M. Khalil, R. Tayyem, S. Qammaz, G. Oriquat, I. A. Basheti, H. Chrystyn. Indacaterol determination in human urine: Validation of a liquid-liquid extraction and liquid chromatography-tandem mass spectrometry analytical method, Journal of Aerosol Medicine and Pulmonary Drug Delivery. 2014. DOI 10.1089/jamp.2014.1153.

[13] C. Emotte, O. Heudi, F. Deglave, A. Bonvie, L. Masson, F. Picard, A. Chaturvedi, T. Majumdar, A. Agarwal, R. Woessner, O. Kretz. Validation of an on-line solid-phase extraction method coupled to liquid chromatography-tandem mass spectrometry detection for the determination of indacaterol in human serum, Journal of Chromatography B-Analytical Technologies in the Biomedical and Life Sciences. Vol.895, 1-9, 2012.

[14] The FDA. The U.S. Food and drug administration guidance for industry: Bioanalytical method validation. [Accessed 01 October 2012]. Online Available from: http://www.fda.gov/downloads/Drugs/Guidances/ucm070107.p df

[15] The EMA. The european medicines agency guideline on bioanalytical method validation. [Accessed 01 October 2011]. Online Available from:

http://www.ema.europa.eu/docs/en GB/document_library/Scie ntific_guideline/2011/08/WC500109686.pdf.

[16] J. Beier, K. M. Beeh. Long-acting beta-adrenoceptor agonists in the management of COPD: Focus on indacaterol, International journal of chronic obstructive pulmonary disease. Vol.6, 237-243, 2011 